Article

\title{
Combinatorial Effects of Soluble, Insoluble, and Organic Extracts from Jerusalem Artichokes on Gut Microbiota in Mice
}

\author{
Hiroyuki Sasaki ${ }^{1}$, Yijin Lyu ${ }^{1}$, Yuki Nakayama ${ }^{1}$, Fumiaki Nakamura ${ }^{2}$, Aya Watanabe ${ }^{1}$, \\ Hiroki Miyakawa ${ }^{1}$, Yoichi Nakao ${ }^{2,3}$ and Shigenobu Shibata ${ }^{1,3, * \text { (D) }}$ \\ 1 Laboratory of Physiology and Pharmacology, School of Advanced Science and Engineering, \\ Waseda University, Shinjuku-ku, Tokyo 162-8480, Japan; hiroyuki-sasaki@asagi.waseda.jp (H.S.); \\ ikin@fuji.waseda.jp (Y.L.); yukibecky-6991@akane.waseda.jp (Y.N.); \\ aya_watanabe7115@suou.waseda.jp (A.W.); hgbbst-hiroki@toki.waseda.jp (H.M.) \\ 2 Laboratory of Chemical biology, School of Advanced Science and Engineering, Waseda University, \\ Shinjuku-ku, Tokyo 162-8480, Japan; what-will_be.x2@akane.waseda.jp (F.N.); ayocha@waseda.jp (Y.N.) \\ 3 Research Institute for Science and Engineering, Waseda University, 3-4-1 Okubo, Shinjuku-ku, \\ Tokyo 169-8555, Japan \\ * Correspondence: shibatas@waseda.jp; Tel.: +81-3-5369-7318
}

Received: 29 May 2020; Accepted: 23 June 2020; Published: 24 June 2020

check for updates

\begin{abstract}
Jerusalem artichokes contain high amounts of inulin, which is a prebiotic that supports digestive health, as well as a variety of insoluble fibers and caffeoylquinic acid. The individual impact of these components on gut microbiota is well known; however, the combinatorial effects are less clear. In this investigation, we fractionated Jerusalem artichokes into three parts (water-soluble extract, insoluble extract, and organic extract) and powdered them. Mice were fed a high-fat diet that included one or more of these extracts for 10 days, and then their cecal $\mathrm{pH}$, cecal short-chain fatty acids (SCFAs), and fecal microbiota were evaluated. The combination of the water-soluble and organic extract decreased cecal $\mathrm{pH}$ and increased the concentration of SCFAs and led to dynamic changes in the composition of the gut microbiota. These results demonstrate that both the water-soluble and organic extracts in Jerusalem artichokes are bioactive substances that are capable of changing SCFA production and the composition of gut microbiota. Powdered Jerusalem artichokes, rather than inulin supplements, may be superior for promoting a healthy gut.
\end{abstract}

Keywords: microbiota; Jerusalem artichoke; inulin; organic-soluble materials

\section{Introduction}

There are nearly 40 trillion bacteria residing in the intestines of mammals, which comprise the microbiota. Dysbiosis, or imbalance between good and bad bacterial populations in the gut, has been reported to be involved in the development of various diseases [1]. For example, high concentrations of Firmicutes have been implicated in an increased risk of obesity, whereas an abundance of Bacteroidetes appears to suppress body fat accumulation [2]. In an investigation that transplanted germ-free mice with feces from obese and lean mice, the recipients of the former became obese [3]. Other pathogenic bacteria, such as Fusobacterium and Fusobacterium nucleatum, have been observed in greater amounts among patients with colorectal cancer compared to healthy counterparts [4,5], and for patients with major depression, unusually high levels of Bacteroidetes, Proteobacteria, and Actinobacteria have been detected [6].

Short-chain fatty acids (SCFAs) are produced from the bacterial fermentation and degradation of resistant starches and dietary fibers [7], and they are known to suppress the growth of pathogenic 
bacteria by lowering intestinal $\mathrm{pH}$, as well as help to regulate metabolism and the immune system [8]. Of the various SCFAs, acetic acid serves as an energy substrate for the liver, propionic acid participates in gluconeogenesis, and butyric acid promotes the induction of regulatory T-cells in the large intestine $[9,10]$.

The composition of microbiota changes in response to the nutritional components of foods consumed, especially those rich in dietary fiber [11]. Often termed prebiotics, dietary fibers are described as nondigestible food ingredients that beneficially affect the host by selectively stimulating the growth and/or activity of one or a limited number of bacterial species already resident in the colon, and thus attempt to improve host health [12]. Inulin, a prominent water-soluble dietary fiber, has gained considerable attention from researchers due to its ability promote mineral absorption [13-15], keep blood sugar stable [16], enhance lipid metabolism [16], treat inflammatory bowel disease [17], and improve the composition of microbiota [18,19].

In recent years, contemporary reports have discovered inulin to be particularly concentrated in Jerusalem artichokes [20,21], and it has generally been recognized as the main component responsible for improvements in microbiota [22-25]. However, to this point, it is well known that vegetables also contain other functional substances such as insoluble dietary fiber, which boosts intestinal health by absorbing water and increasing stool volume to promote peristalsis and defecation [26,27]. Thus, it is presumable that other factors in Jerusalem artichokes may be contributing to its health-promoting properties. Notably, the insoluble fiber, caffeoylquinic acid, coumarin, lectins, and sesquiterpenes [28-31] present in Jerusalem have been proven to possess bioactivity, although their direct impact on gut microbiota remains to be elucidated.

In this study, we investigated the effects of Jerusalem artichokes versus pure inulin on intestinal microbiota in mice fed a high-fat diet (HFD), aiming specifically to identify: (1) the effects of Jerusalem artichokes versus inulin on microbiota, (2) the effects of water-soluble versus insoluble dietary fiber on microbiota, and (3) the effects of organic extracts from Jerusalem artichokes on microbiota. Mice were fed this diet because previous research by our team demonstrated that inulin helps to blunt the injurious effects of HFDs [19]. Additionally, based on preliminary data, Jerusalem artichokes exert stronger effects on the microbiota rather than inulin alone, so this vegetable was fractionated into three parts: water-soluble extract (rich in inulin), insoluble extract, and organic extract in order to carry out the aims listed above. We hypothesized that Jerusalem artichokes would change the composition of microbiota due to their high inulin content, but this effect would be weaker than that of pure inulin.

\section{Materials and Methods}

\subsection{Animals}

Male ICR mice ( $n=94,8$ weeks of age) were purchased from Tokyo Laboratory Animals (Tokyo, Japan). They were housed in individual cages and kept in a room maintained on a $12 \mathrm{~h}$ light/12 h dark cycle at $22{ }^{\circ} \mathrm{C}, 60 \%$ humidity, and a light intensity of 100-150 lux. Light-on time was defined as zeitgeber time 0 (ZT0) and lights-off time was defined as ZT12. The mice were given a HFD consisting of 45\% kcal from fat (Diet 12451; Research Diets Inc., New Brunswick, NJ, USA), cellulose (Oriental Yeast Co., Ltd., Tokyo, Japan), inulin (Fuji FF; Fuji Nihon Seito Co., Tokyo, Japan), and one or more extractions of Jerusalem artichoke powder (Yasai Factory Co., Ltd, Osaka, Japan) (see Table 1). Experiments were conducted with permission from the Committee for Animal Experimentation of the School of Science and Engineering at Waseda University (permission \# 09A11, 10A11), as well as in accordance with the Law (No. 105) and Notification (No. 6) of the Japanese Government. 
Table 1. Nutritional information of the Jerusalem artichoke powder (10 g).

\begin{tabular}{cc}
\hline Energy & $37 \mathrm{kcal}$ \\
\hline Protein & $0.9 \mathrm{~g}$ \\
\hline Fat & $0.2 \mathrm{~g}$ \\
\hline Carbohydrates & $7.7 \mathrm{~g}$ \\
\hline Salt & $0.0 \mathrm{~g}$ \\
\hline
\end{tabular}

\subsection{Fractioning the Jerusalem Artichoke}

Jerusalem artichoke powder was dissolved in water and centrifuged $(450 \times g, 1 \mathrm{~min}$, room temperature) to separate the water-soluble layer from the insoluble layer. Each layer was freeze-dried for three days to become powdered. Since there was the possibility that some of the water-soluble and insoluble extracts may not have fully separated into their respective layers following centrifugation, the insoluble extract was washed several times with water using filter bell (\#1 paper filter in ADVANTEC), and the water-soluble layer was freeze-dried for three days to become powdered. The fraction extracted with water was deemed the "water-soluble extract". The fraction extracted with methanol and chloroform (1:1) using a filter bell (\#1 paper filter in ADVANTEC) was deemed the "organic extract". The fraction not extracted with water, methanol, or chloroform was deemed the "insoluble extract". Each extract was freeze-dried for three days and then powdered (Figure 1).

A

Jerusalem Artichoke powder

Powder name : A

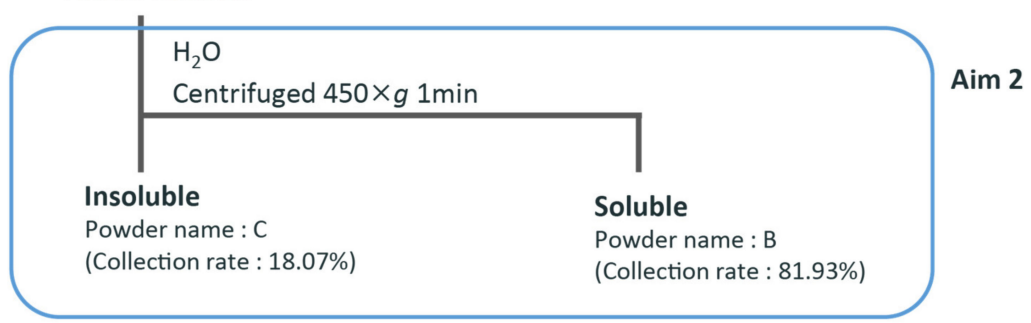

B

Jerusalem Artichoke powder

Powder name : A

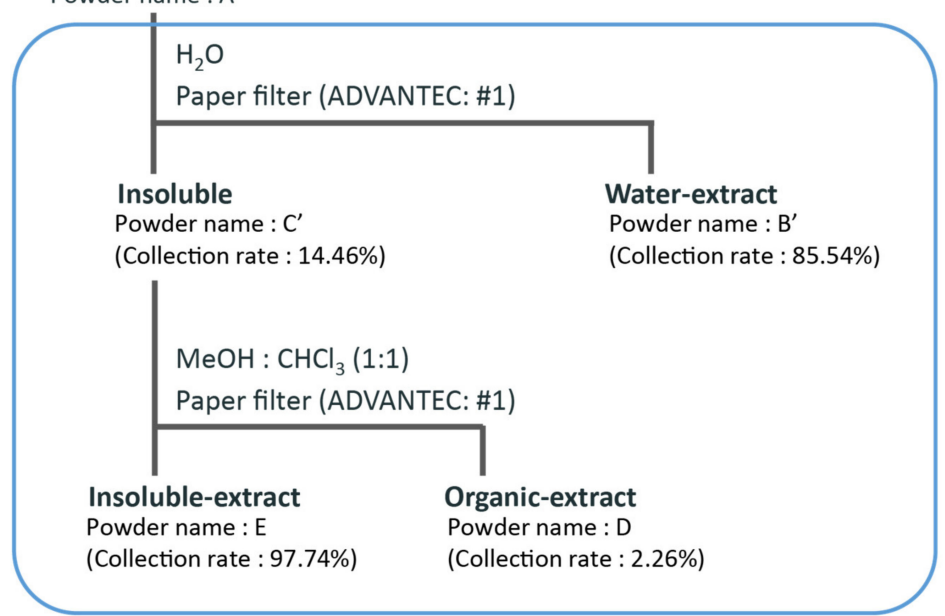

Aim 3

Figure 1. Fractionation scheme for (A) aim 2 and (B) aim 3. 


\subsection{Determining the Inulin/Fructan Content}

The amounts of fructan in each extract were determined by the K-FRUC Fructan Assay Kit (Megazyme, Bray, Ireland). This kit can determine the amount of natural fructan and levan-type fructan present. If the fructan is natural, all molecular weights are included in the measurement. If it includes hydrolytic fructans, the amount of fructan will be underestimated by approximately $20 \%$, because the sugars will be reduced to sugar alcohols.

\subsection{Experimental Design}

For the first aim, mice were fed a HFD with $2.5 \%$ cellulose (cellulose group), $2.5 \%$ inulin (inulin group), or $2.5 \%$ Jerusalem artichoke powder (Jerusalem artichoke group) for 10 days. After the feeding period, mice were sacrificed at ZT4 (i.e., $4 \mathrm{~h}$ after the onset of the light phase). Cecal $\mathrm{pH}$ was measured, and cecal contents and feces were collected.

For the second aim, mice were fed a HFD with 2.5\% cellulose (control group), 2.5\% Jerusalem artichoke powder (A group), 2.5\% soluble powder (B group), 2.5\% insoluble powder (C group), or $1.25 \%$ soluble $+1.25 \%$ insoluble powder $(B+C$ group) for 10 days. After the feeding period, mice were sacrificed at ZT4. Cecal pH was measured, and cecal contents and feces were collected.

For the third aim, mice were fed a HFD with 2.5\% cellulose (control group), 2.5\% Jerusalem artichoke powder (A group), 2.5\% water-soluble extract ( $\mathrm{B}^{\prime}$ group), 2.5\% organic extract (D group), 2.5\% insoluble extract (E group), 1.25\% water-soluble extract $+1.25 \%$ organic extract ( $\mathrm{B}^{\prime}+\mathrm{D}$ group), or $1.25 \%$ water-soluble extract $+1.25 \%$ insoluble extract $\left(B^{\prime}+E\right.$ group) for 10 days. After the feeding period, mice were sacrificed at ZT4. Cecal pH was measured, and cecal contents and feces were collected.

\subsection{Cecal $\mathrm{pH}$ Measurement}

Cecal $\mathrm{pH}$ was measured by inserting an electrode from a $\mathrm{pH}$ meter (pH Spear; Eutech Instruments, Vernon Hills, IL, USA) directly into the cecum.

\subsection{SCFA Measurement}

SCFAs were measured using gas chromatography and a flame ionization detector (Shimadzu Corp., Kyoto, Japan), as described by a previous report [32] with some modifications. A total of $0.05 \mathrm{~g}$ of cecal contents were acidified with $0.05 \mathrm{~mL}$ of sulfuric acid (FUJIFILM Wako Pure Chemical Corp., Osaka, Japan). Then, the SCFAs were extracted with a mixture of $0.4 \mathrm{~mL}$ of diethyl ether (FUJIFILM Wako Pure Chemical Corp., Osaka, Japan) and $0.2 \mathrm{~mL}$ of ethanol (FUJIFILM Wako Pure Chemical Corp., Osaka, Japan), and centrifuged at $18,700 \times g$ for $30 \mathrm{~s}$. A total of $1 \mu \mathrm{L}$ of the organic phase was injected into a capillary column (InertCap Pure WAX (30 $\mathrm{m} \times 0.25 \mathrm{~mm}, \mathrm{df}=0.5 \mathrm{um})$ GL Science Inc., Tokyo, Japan) with an initial temperature of $80^{\circ} \mathrm{C}$ and final temperature of $200{ }^{\circ} \mathrm{C}$; helium was used as the carrier gas.

\subsection{DNA Extraction from Feces}

Fecal DNA extraction was performed as previously described, with modifications [33]. About 0.2 $\mathrm{g}$ of the fecal sample was mixed with $20 \mathrm{~mL}$ of PBS (Phosphate-buffered saline) and filtered through a $100 \mu \mathrm{m}$ mesh nylon filter (Corning Inc., Corning, NY, USA). The debris on the filter was washed with $10 \mathrm{~mL}$ of PBS, and the filtrates were centrifuged at $9000 \times \mathrm{g}$ for $20 \mathrm{~min}$ at $4{ }^{\circ} \mathrm{C}$. Each precipitate was suspended with $1.5 \mathrm{~mL}$ of TE10 buffer $(10 \mathrm{mM}$ Tris-HCl, FUJIFILM Wako Pure Chemical Corp., Osaka, Japan/10 mM EDTA (Ethylenediamine tetraacetic acid), DOJINDO, Tokyo, Japan), centrifuged at $9560 \times \mathrm{g}$ for $5 \mathrm{~min}$ at $4{ }^{\circ} \mathrm{C}$ and then suspended with $0.8 \mathrm{~mL}$ TE10 buffer. DNA was extracted using $1 \mathrm{~mL}$ PCI (Invitrogen, Carlsbad, CA, USA), and isolated using $0.1 \mathrm{~mL}$ lysozyme (FUJIFILM Wako Pure Chemical Corp., Osaka, Japan) and $0.02 \mathrm{~mL}$ achromopeptidase (FUJIFILM Wako Pure Chemical Corp., Osaka, Japan). DNA was purified using RNase (Promega Corp., WI, USA) and precipitated with 20\% 
PEG (Polyethylene glycol) solution (Tokyo Chemical Industry Co., Ltd., Tokyo, Japan). It was rinsed with $70 \%$ ethanol and dissolved in $50 \mu \mathrm{L}$ TE (Tris-EDTA) buffer.

\subsection{S rDNA Gene Sequencing}

The $16 \mathrm{~S}$ rDNA gene sequencing was performed according to the instructions of Illumina Inc. (San Diego, CA, USA). V3-V4 variable regions of the $16 \mathrm{~S}$ rDNA gene were amplified by PCR using the following primers: Forward Primer = 5'-TCGTCGGCAGCGTCAGATGTGTATAAGAGACAGCCTACGGGNGGCWGCAG-3', Reverse Primer $=5^{\prime}$-GTCTCGTGGGCTCGGAGATGTGTATAAGAGACAGGACTACHVGGGTATCTAATCC $-3^{\prime}$.

PCR amplification was carried out using $2.5 \mu \mathrm{L}$ microbial DNA $(5 \mathrm{ng} / \mu \mathrm{L}), 5 \mu \mathrm{L}$ of each primer $(1 \mu \mathrm{mol} / \mathrm{L})$, and $12.5 \mu \mathrm{L} 2 \times$ KAPA HiFi HotStart Ready Mix (Kapa Biosystems Inc., Wilmington, MA, USA). It was performed at the following settings: $95^{\circ} \mathrm{C}$ for $3 \mathrm{~min}$, followed by 25 cycles at $95^{\circ} \mathrm{C}$ for $30 \mathrm{~s}, 55^{\circ} \mathrm{C}$ for $30 \mathrm{~s}$, and $72{ }^{\circ} \mathrm{C}$ for $30 \mathrm{~s}$. Finally, an extension was carried out at $72{ }^{\circ} \mathrm{C}$ for $5 \mathrm{~min}$. The Amplicon PCR products were purified using AMPure XP beads (Beckman Coulter Inc., Brea, CA, USA) according to the manufacturer's instructions. A Nextera XT Index kit v. 2 (Illumina Inc., San Diego, CA, USA) was used for the Illumina sequencing adapters and attachment of the dual indices. An index PCR was carried out using 5.0 $\mu \mathrm{L}$ PCR production, $5.0 \mu \mathrm{L}$ Nextera XT Index Primer, $25 \mu \mathrm{L} 2 \times$ KAPA HiFi HotStart Ready Mix, and $10 \mu \mathrm{L}$ PCR-grade water. PCR was performed at the following settings: $95{ }^{\circ} \mathrm{C}$ for $3 \mathrm{~min}$, followed by 8 cycles at $95^{\circ} \mathrm{C}$ for $30 \mathrm{~s}, 55^{\circ} \mathrm{C}$ for $30 \mathrm{~s}$, and $72{ }^{\circ} \mathrm{C}$ for $30 \mathrm{~s}$. Finally, an extension was carried out at $72{ }^{\circ} \mathrm{C}$ for $5 \mathrm{~min}$. The index PCR products were purified using the AMPure XP beads (Beckman Coulter Inc., Brea, CA, USA). The quality of the purifications was evaluated using Agilent 2100 Bioanalyzer with a DNA1000 kit (Agilent Technologies Inc., Santa Clara, CA, USA). Then, the DNA library was diluted to $4 \mathrm{nmol} / \mathrm{L}$.

The DNA library was sequenced using the Miseq reagent kit v. 3 (Illumina Inc., San Diego, CA, USA) in the Illumina Miseq $2 \times 300 \mathrm{bp}$ platform. This sequencing was performed according to the manufacturer's instructions.

\subsection{Analysis of $16 S \mathrm{rDNA}$ Gene Sequences}

Then, 16S rDNA sequencing reads were processed by the Quantitative Insights into Microbial Ecology (QIIME) pipeline v. 1.9.1 [34]. Then, the reads were assigned to operational taxonomic units (OTUs) at 97\% identity with the UCLUST algorithm [35] and then compared to reference sequences in the Greengenes database (v. August 2013). A total of 3,197,966 reads was obtained from 94 samples; on average, $34,020 \pm 2666$ reads were obtained per sample. The taxonomy summary at the phylum and genus levels, the alpha diversity index (e.g., Simpson diversity), beta diversity index, and principal coordinate analysis (PCoA) were calculated using QIIME. A PCoA analysis was also calculated using unweighted UniFrac distances.

\subsection{Statistical Analysis}

The D'Agostino-Pearson test/Kolmogorov-Smirnov test and Bartlett's test analyzed the data for normal or non-normal distributions, and equal or biased variations, respectively. If the data showed a normal distribution and equal variation, statistical significance was determined using one-way analysis of variance with a Tukey Test for post-hoc analysis. If the data showed a non-normal distribution or biased variation, statistical significance was determined using the Kruskal-Wallis test with Dunn's Multiple Comparison Test for post-hoc analysis. A permutational multivariate analysis of variance (PERMANOVA) was performed by QIIME and used to assess changes in composition of the microbiota. All data are expressed as means \pm standard error of the mean (SEM); $p<0.05$ was considered statistically significant. Statistical analyses were performed using the GraphPad Prism v. 6.03 (GraphPad Software Inc., San Diego, CA, USA). 


\section{Results}

\subsection{Aim 1: Consumption of Jerusalem Artichokes Led to Greater Changes in Microbiota Composition than Inulin}

In a preliminary experiment, we discovered that a HFD changed cecal $\mathrm{pH}$ and SCFA content when compared to a standard (EF) diet (Oriental Yeast Co. Ltd., Tokyo, Japan). Specifically, cecal pH (Supplementary Figure S1A) and levels of SCFAs (Supplementary Figure S1B-E) were found to be significantly higher and lower, respectively, in the HFD group than the EF diet group. In light of these findings, it was plausible that feeding mice a HFD may be an effective way to induce abnormal conditions for their microbiota.

The amount of fructan in inulin and Jerusalem artichokes was found to be nearly $100 \%$ and $40 \%$, respectively (Figure 2A). No significant differences in food intake or change in body weight over the 10 days were observed among the groups (Figure 2B,C). Cecal pH was found to be significantly lower in the inulin and Jerusalem artichoke groups than the cellulose group (Figure 2D). Levels of acetic acid were higher for the inulin group when compared to the cellulose group (Figure 2E). Levels of lactic acid were significantly higher for the Jerusalem artichoke group when compared to the cellulose group (Figure 2G). Levels of propionic and butyric acid were significantly higher in the inulin and Jerusalem artichoke groups when compared to the cellulose group (Figure 2F,H).

Analyses revealed that the Simpson diversity index was not significantly different between the inulin and Jerusalem artichoke groups (Figure 2I). The beta diversity index was significantly different between the cellulose and inulin groups, the cellulose and Jerusalem artichoke groups, and the inulin and Jerusalem artichoke groups (Figure 3B-D, respectively).

A

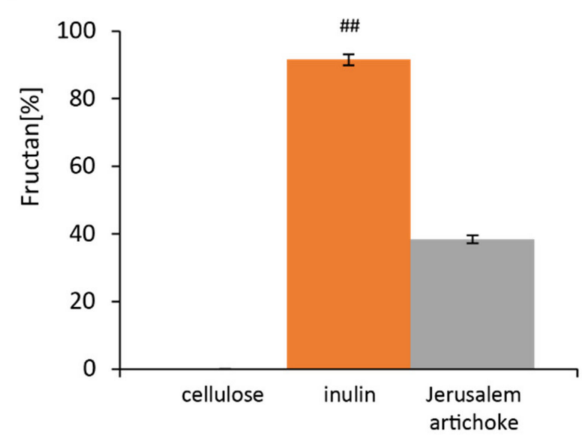

B

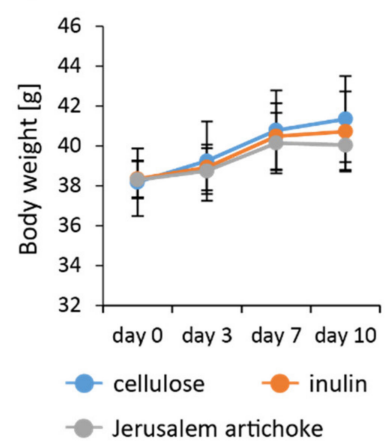

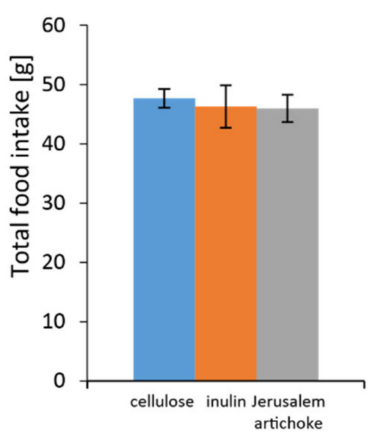

$\mathbf{F}$

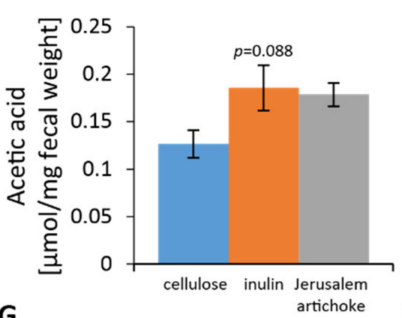

G

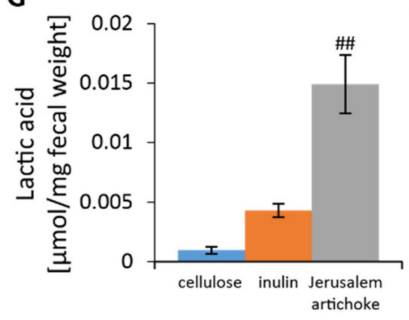

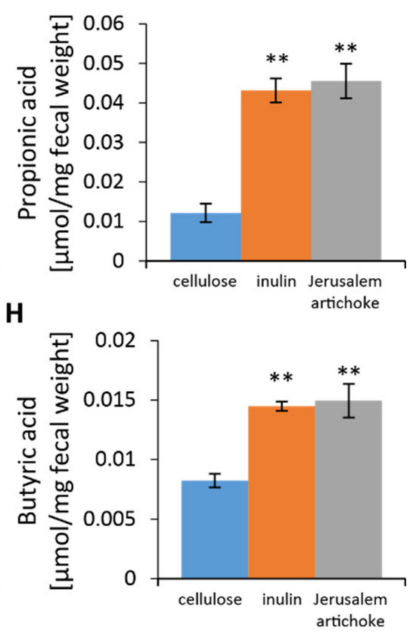

Figure 2. Consumptions of Jerusalem artichokes decreased cecal $\mathrm{pH}$ and increased levels of short-chain fatty acids similar to that of inulin. (A) The amount of fructan (cellulose $(n=4)$, inulin $(n=4)$, Jerusalem 
artichoke $(n=4))$. (B) Change in body weight after 10 days. (C) Total food intake over 10 days. (D) Cecal $\mathrm{pH}$ of mice housed for 10 days for each group. (E-H) SCFAs of mice for 10 days, including (E) acetic acid, (F) propionic acid, (G) lactic acid, and (H) butyric acid. (I) Bacterial alpha diversity. Comparison of the Simpson diversity index for the $16 \mathrm{~S}$ rDNA gene libraries at $97 \%$ similarity, per the sequencing analysis. All values are represented as mean \pm SEM (cellulose $(n=9)$, inulin $(n=9)$, Jerusalem artichoke $(n=9))$. ${ }^{* *} p<0.01$ versus cellulose, evaluated using one-way ANOVA with Tukey post-hoc test. \#\# $p<0.01$ vs. cellulose, evaluated using the Kruskal-Wallis with Dunn post-hoc test.

A

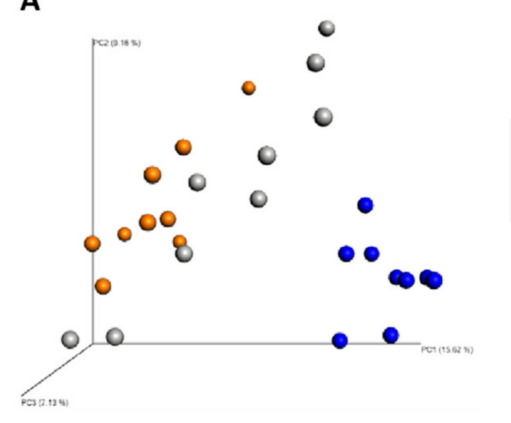

Cellulose

Inulin

Jerusalem artichoke

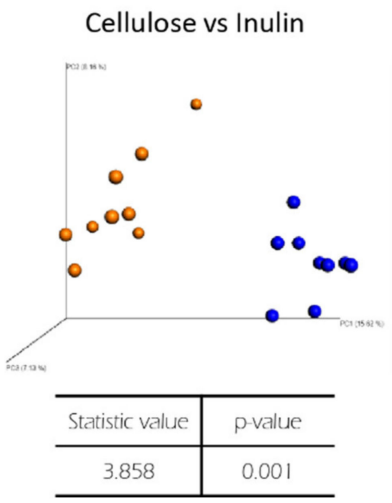

C

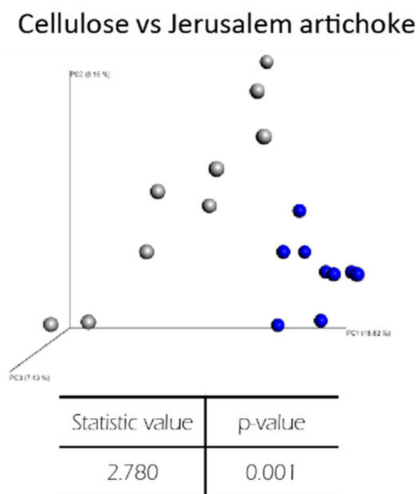

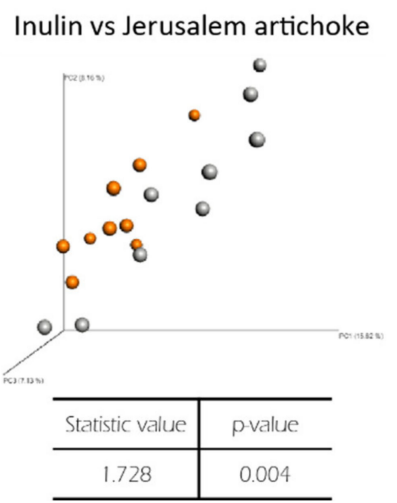

Figure 3. The microbiota compositions differed across all experimental groups. Bacterial beta diversity index for comparing (A) each group, (B) cellulose and inulin, (C) cellulose and Jerusalem artichoke, or (D) inulin and Jerusalem artichoke. The principal coordinate analysis (PCoA) plots of unweighted UniFrac distance metrics obtained from sequencing the $16 \mathrm{~S}$ rDNA gene in feces (cellulose $(n=9)$, inulin $(n=9)$, Jerusalem artichoke $(n=9))$. The table in these figures indicate the result using PERMANOVA.

The relative abundance of Actinobacteria was significantly higher in the inulin group than the cellulose group (Figure 4A). The relative abundances of Lactococcus and Oscillospira were significantly lower in the inulin and Jerusalem artichoke groups compared to the cellulose group (Figure 4I,K).

Bifidobacterium, Parabacteroides, Streptococcus, and Allobaculum experienced greater changes in the inulin group than the cellulose group (Figure 4D,F,J, L). Prevotella and Lactobacillus experienced more changes in the Jerusalem artichoke group than the cellulose group (Figure $4 \mathrm{G}, \mathrm{H}$ ). 
A

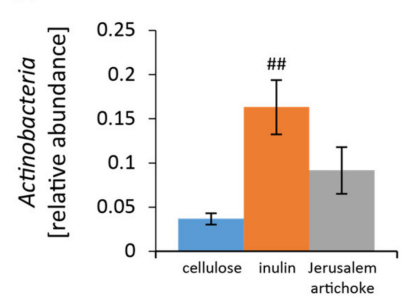

D

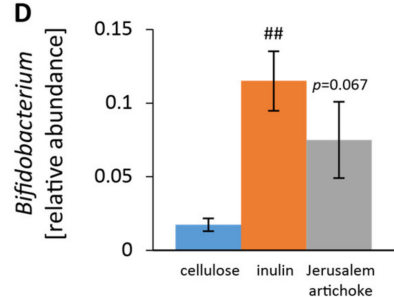

G

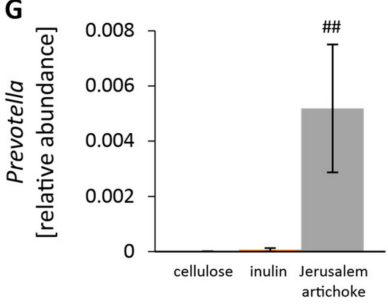

J

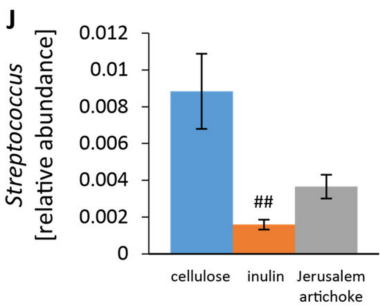

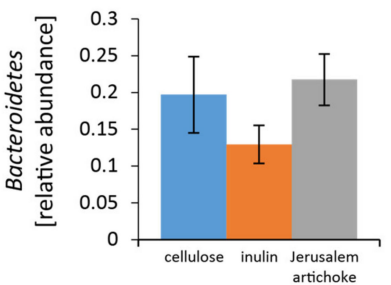

E

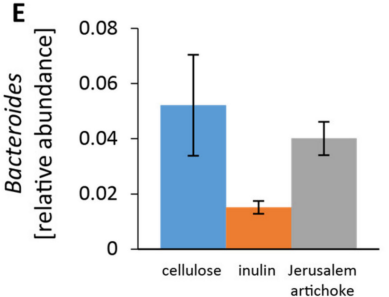

H

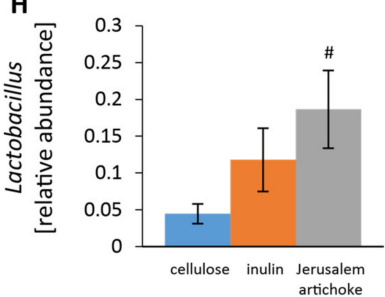

K

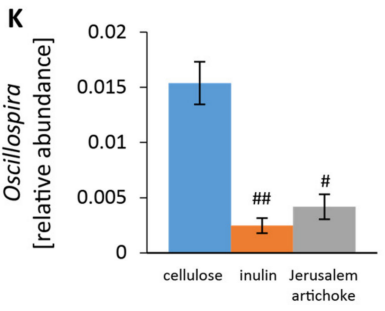

C

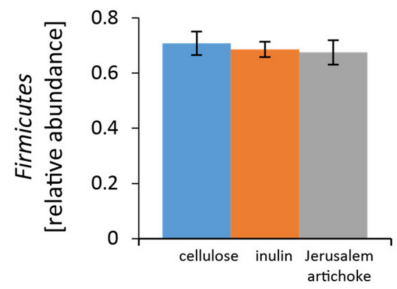

F

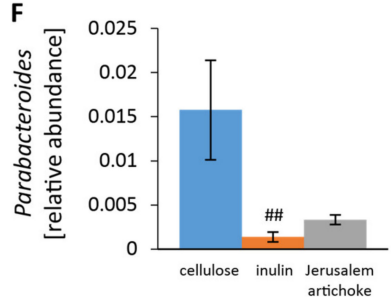

I

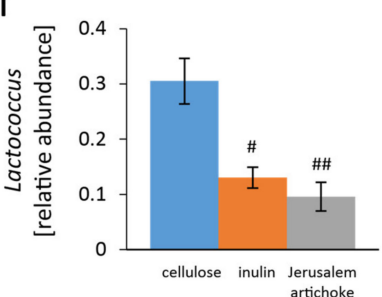

L

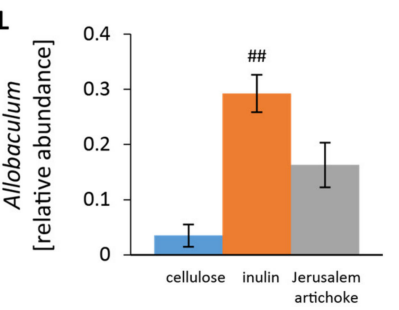

Figure 4. The relative abundance of microbes at the phylum and genus levels was changed upon consumption of inulin and the Jerusalem artichoke. (A-C) The relative abundance of microbes at the phylum level ((A) Actinobacteria, (B) Bacteroidetes, (C) Firmicutes). (D-L) The relative abundance of microbes at the genus level ((D) Bifidobacterium, (E) Bacteroides, (F) Parabacteroides, (G) Prevotella, (H) Lactobacillus, (I) Lactococcus, (J) Streptococcus, (K) Oscillospira, (L) Allobaculum). All values are represented as mean \pm SEM (cellulose $(n=9)$, inulin $(n=9)$, Jerusalem artichoke $(n=9))$. \#\# $p<0.01$, $\# p<0.05$ vs. cellulose, evaluated using the Kruskal-Wallis with Dunn post-hoc test.

3.2. Aim 2: Consumption of Both the Water-Soluble and Insoluble Components in Jerusalem Artichokes Changed the Composition of the Microbiota

We thought that the insoluble dietary fiber of Jerusalem artichoke might explain the reason why Jerusalem artichoke showed a different microbiota composition from inulin. Therefore, Jerusalem artichoke was dissolved in water and separated into a water layer and a precipitate layer by centrifugation; then, each layer was powdered by freeze-drying and given to mice for 10 days (Figure 1A).

The water-soluble components in the Jerusalem artichoke were found to consist of almost $60 \%$ fructan (Figure 5A). No significant differences in food intake or change in body weight over the 10 days were observed among the five groups (Figure $5 \mathrm{~B}, \mathrm{C}$ ). Cecal $\mathrm{pH}$ was significantly lower in groups A and $B+C$ than the control group (Figure 5D). Levels of acetic acid were significantly higher in group B than the control group and group C (Figure 5E). Levels of propionic and lactic acid were significantly higher in groups $A$ and $B+C$ than the control group (Figure $5 F, G$ ). Levels of butyric acid were significantly higher in groups $A, B$, and $B+C$ than the control group (Figure $5 \mathrm{H}$ ). 
A

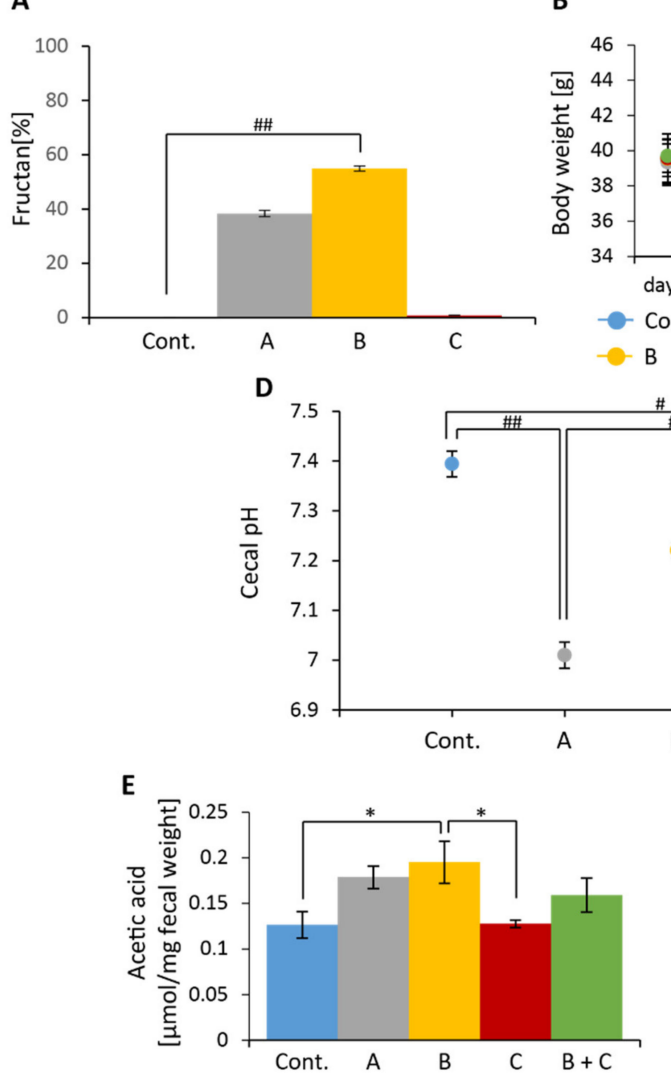

G
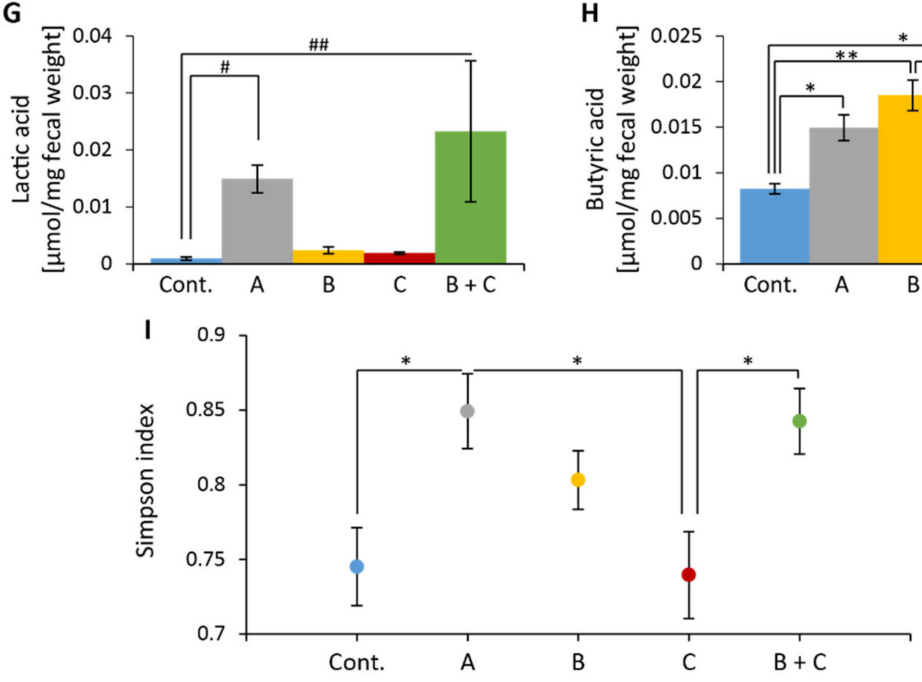

H

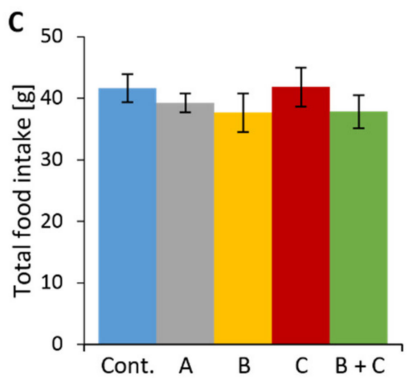

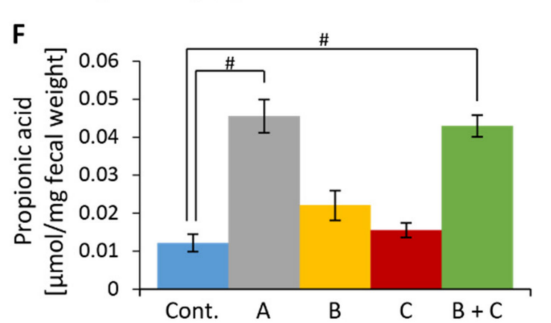
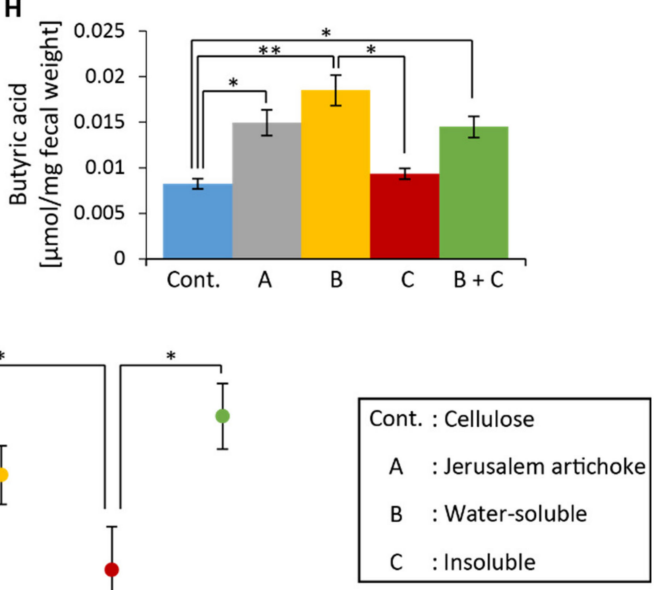

Figure 5. The Jerusalem artichoke, and the combination of water-soluble and insoluble extracts, decreased cecal $\mathrm{pH}$, and increased levels of short-chain fatty acids. (A) The amount of fructan (cellulose $(n=4)$, Jerusalem artichoke $(n=4)$, water-soluble $(n=4)$, insoluble $(n=4))$. (B) Change in body weight after 10 days. (C) Total food intake over 10 days. (D) Cecal $\mathrm{pH}$ of mice housed for 10 days for each group. (E-H) Short-chain fatty acids (SCFAs) of mice for 10 days, including (E) acetic acid, (F) propionic acid, (G) lactic acid, and (H) butyric acid. (I) Bacterial alpha diversity. Comparison of the Simpson diversity index for the $16 \mathrm{~S}$ rDNA gene libraries at 97\% similarity, per the sequencing analysis. All values are represented as mean \pm SEM (cellulose $(n=5)$, Jerusalem artichoke $(n=5)$, soluble $(n=5)$, insoluble $(n=5)$, soluble + insoluble $(n=5)) .{ }^{* *} p<0.01,{ }^{*} p<0.05$, evaluated using One-way ANOVA with Tukey post-hoc test. \#\# $p<0.01$, \# $p<0.05$, evaluated using the Kruskal-Wallis with Dunn post-hoc test. Cellulose, Jerusalem artichoke, water-soluble, or insoluble are Cont., A, B, or C, respectively. 
Analyses revealed that the Simpson index was significantly higher in group A than the control group and group $C$, as well as higher in group B $+C$ than group C (Figure 5I). Per the beta diversity indices, the microbiota composition between group $A$ and $B+C$ group was significantly different, as well as the microbiota composition for the control group and group $C$ against groups $A, B$, and $B+C$ (Figure 6A,B, and Supplementary Table S1).

A

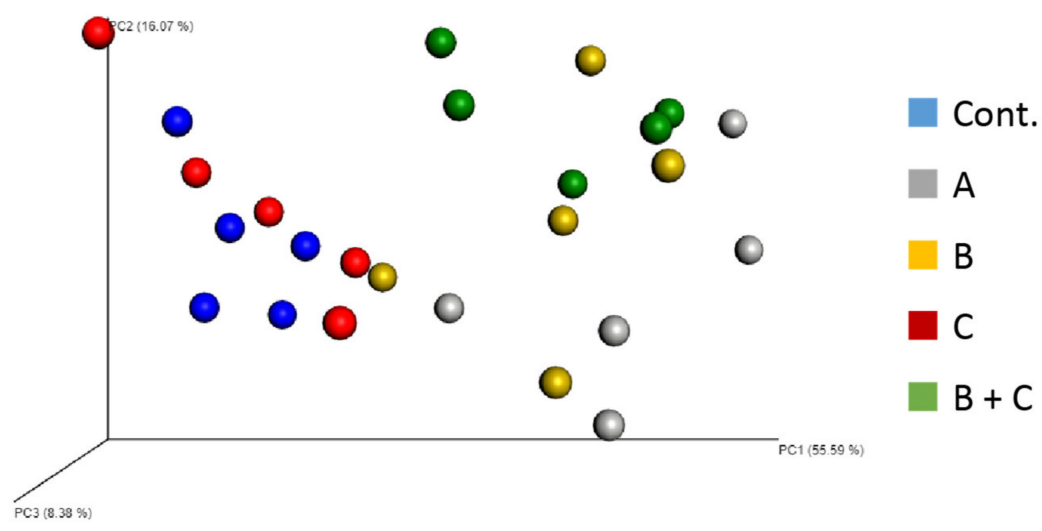

B

\section{Unweighted UniFrac distance}

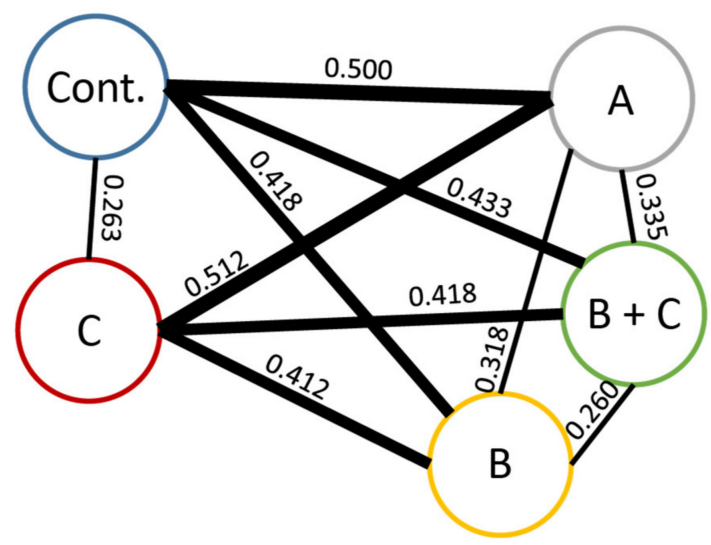

Cont. : Cellulose

A : Jerusalem artichoke

B : Water-soluble

C : Insoluble

Figure 6. The Jerusalem artichoke and water-soluble extracts changed the microbiota composition. (A) Bacterial beta diversity for comparing each group. PCoA plots of unweighted UniFrac distance metrics obtained from sequencing the $16 \mathrm{~S}$ rDNA in feces. (Cellulose $(n=5)$, Jerusalem artichoke $(n=5)$, soluble $(n=5)$, insoluble $(n=5)$, soluble + insoluble $(n=5))$. (B) The average of unweighted UniFrac distance between groups. The number in $(\mathbf{B})$ indicate the average distance calculated by UniFrac distance metrics. Cellulose, Jerusalem artichoke, soluble, or insoluble are Cont., A, B, or C, respectively.

The relative abundance of Actinobacteria was significantly higher in groups A and B than the control group (Figure 7A). The relative abundance of Bacteroidetes was significantly higher in group B $+C$ than group B (Figure 7B). The relative abundance of Streptococcus was significantly lower in groups A, B, and B + C than the control group (Figure 7J). The relative abundance of Parabacteroides was significantly lower in groups B and B $+C$ than the control group (Figure 7F). 
Shifts in levels of Bifidobacterium, Bacteroides, and Oscillospira were greater in groups A, B, and B + $\mathrm{C}$ than the control group (Figure 7D, E, and K, respectively).

A

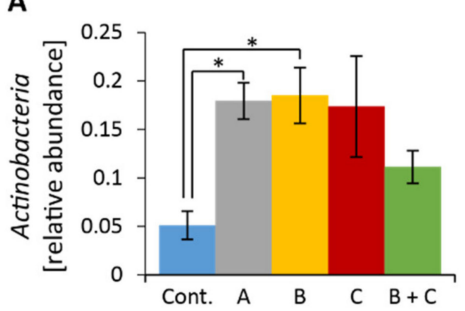

D

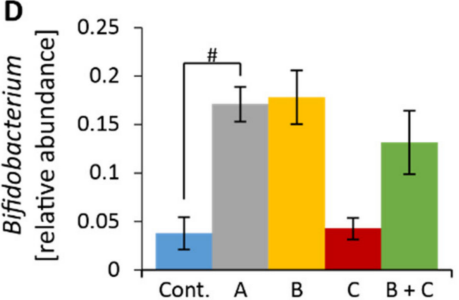

$\mathbf{G}$
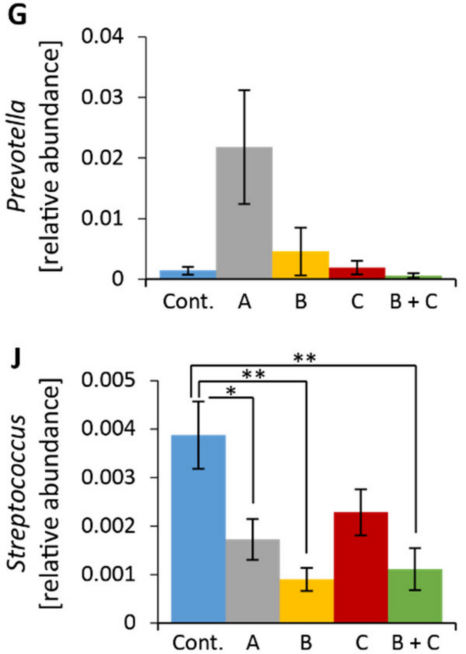

B
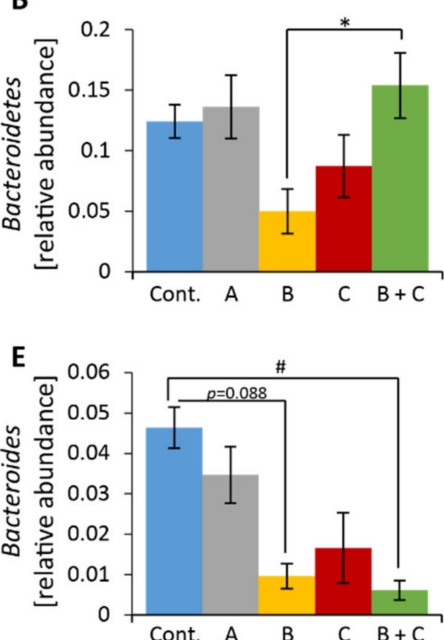

H

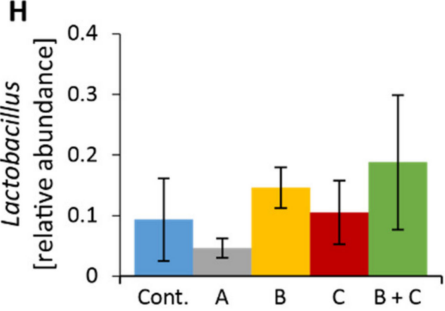

$\mathbf{K}$

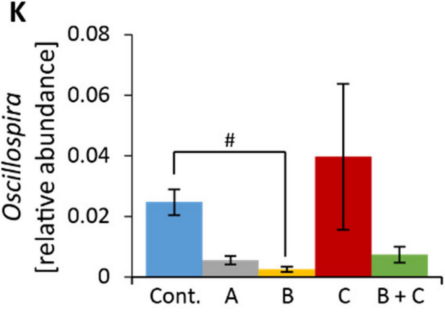

C

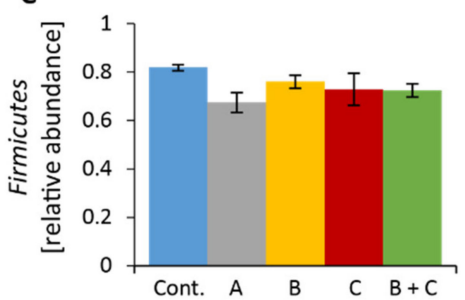

F

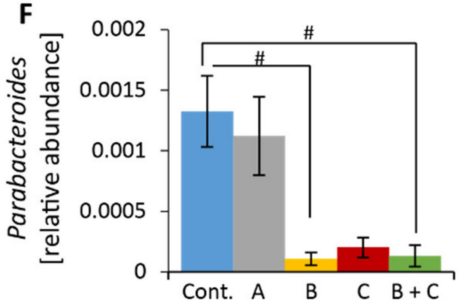

I

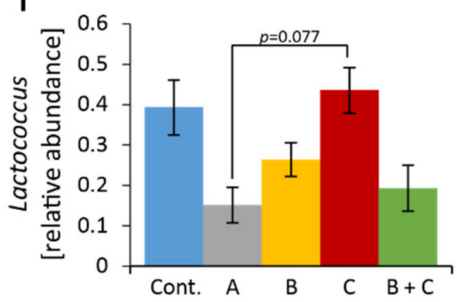

L

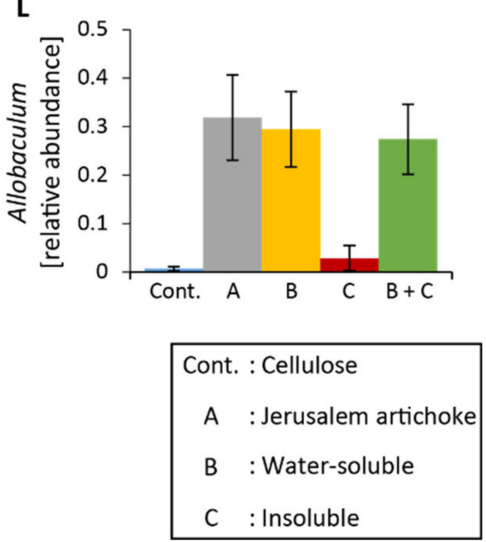

Figure 7. The relative abundance of microbes at the phylum and genus levels was changed upon consumption of the Jerusalem artichoke and the water-soluble extract. (A-C) The relative abundance of microbes at the phylum level ((A) Actinobacteria, (B) Bacteroidetes, (C) Firmicutes). (D-L) The relative abundance of microbes at the genus level ((D) Bifidobacterium, (E) Bacteroides, (F) Parabacteroides, (G) Prevotella, (H) Lactobacillus, (I) Lactococcus, (J) Streptococcus, (K) Oscillospira, and (L) Allobaculum). All values are represented as mean $\pm \operatorname{SEM}$ (cellulose $(n=5)$, Jerusalem artichoke $(n=5)$, water-soluble $(n=$ 5), insoluble $(n=5)$, water-soluble + insoluble $(n=5))$. ${ }^{* *} p<0.01,{ }^{*} p<0.05$, evaluated using one-way ANOVA with Tukey post-hoc test. \# $p<0.05$, evaluated using the Kruskal-Wallis with Dunn post-hoc test. Cellulose, Jerusalem artichoke, water-soluble, or insoluble are Cont., A, B or C, respectively. 


\subsection{Aim 3: The Organic Component in Jerusalem Artichokes Changed the Composition of the Microbiota}

In the preceding aim, group B + C was fed half the amount of fructans as group B; however, both groups exhibited similar changes in microbiota composition. On the other hand, the insoluble group had no effect on the microbiota. In other words, it was possible that the insoluble component provided a strong effect when combination with the soluble component. Therefore, we extracted the organic soluble component using a chloroform/methanol vehicle to find out the role of organic components of Jerusalem artichoke on microbiota (Figure 1B).

No significant differences in food intake or change in body weight over the 10 days were observed among the seven groups (Figure $8 \mathrm{~A}$ and B). Cecal $\mathrm{pH}$ was significantly lower in groups $\mathrm{A}$ and $\mathrm{B}^{\prime}+\mathrm{D}$ than the control group and group $\mathrm{E}$ (Figure $8 \mathrm{C}$ ). Levels of lactic acid were significantly higher in groups $A$ and $B^{\prime}+D$ than the control group (Figure $8 F$ ). Levels of butyric acid were significantly higher in group $\mathrm{A}$ than the control group and groups $\mathrm{D}$ and $\mathrm{E}$, as well as significantly higher in group $\mathrm{B}^{\prime}+\mathrm{D}$ than the control group (Figure 8G).

No significant differences in the Simpson diversity index were detected among the groups (Figure $8 \mathrm{H}$ ). Summarizing the beta diversity indices, the control group and groups A, E, and B' + E exhibited independency from each other, as well as showed significantly different microbiota components than the other groups. Groups B', D, and B' + D displayed a similar microbiota composition, although each was significantly different from the other groups (Figure 9A,B, and Supplementary Table S2). 

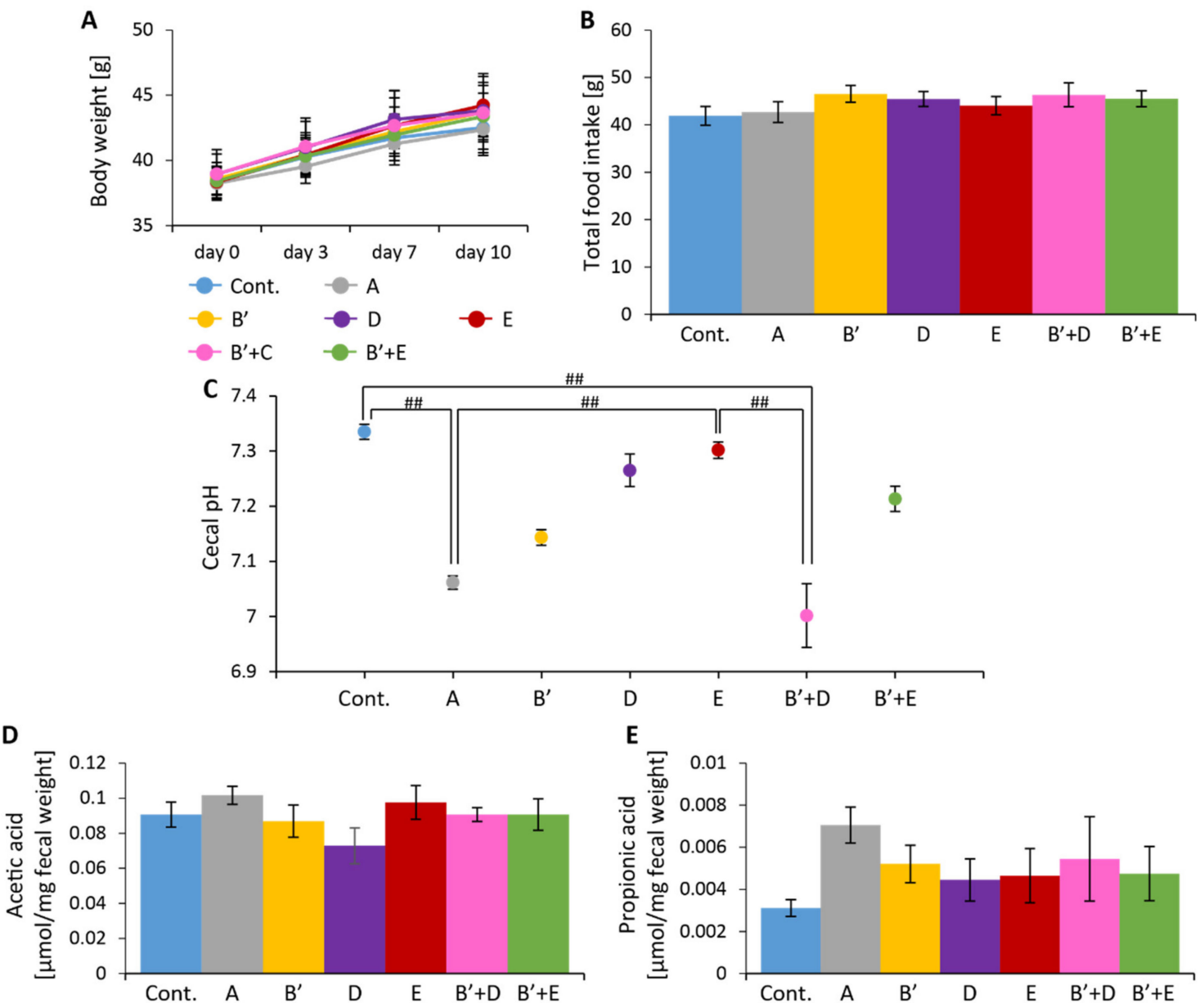

$\mathbf{F}$
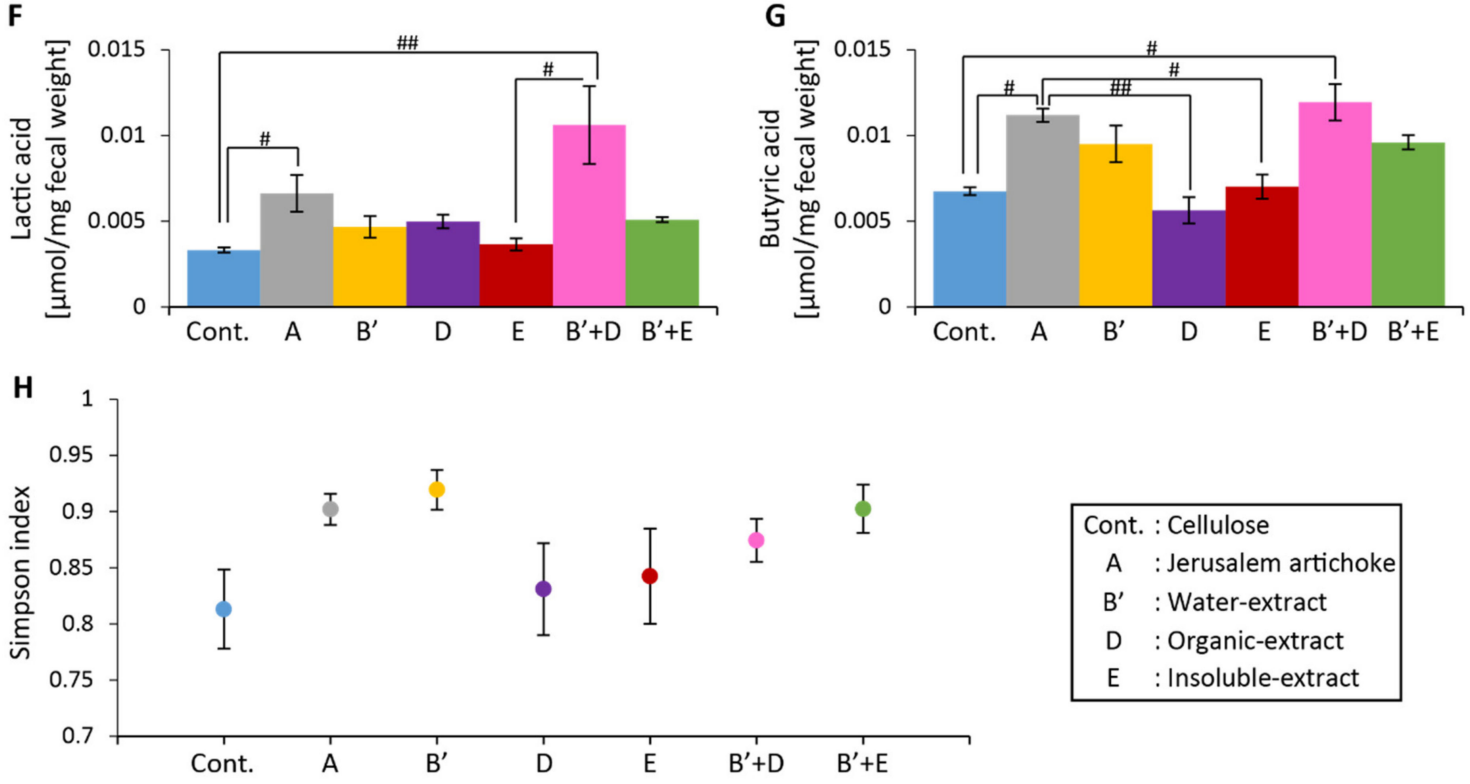

Figure 8. The Jerusalem artichoke, and the combination of the water-soluble and organic extracts, decreased cecal $\mathrm{pH}$, and increased levels of short-chain fatty acids. (A) Change in body weight after 10 days. (B) Total food intake over 10 days. (C) Cecal $\mathrm{pH}$ of mice housed for 10 days for each group. (D-G) SCFAs of mice for 10 days, including (D) acetic acid, (E) propionic acid, (F) lactic acid, and (G) butyric acid. (H) Bacterial alpha diversity. Comparison of the Simpson diversity index for the $16 \mathrm{~S}$ rDNA gene libraries at $97 \%$ similarity, per the sequencing analysis. All values are represented as mean 
\pm SEM (cellulose $(n=6)$, Jerusalem artichoke $(n=6)$, water-soluble extract $(n=6)$, organic extract $(n=6)$, insoluble extract $(n=6)$, water-soluble extract + organic extract $(n=6)$, water-soluble extract + insoluble extract $(n=6))$. \#\# $p<0.01$, \# $p<0.05$, evaluated using the Kruskal-Wallis with Dunn post-hoc test. Cellulose, Jerusalem artichoke, water extract, organic extract, or insoluble extract are Cont., A, B', D or E, respectively.

A

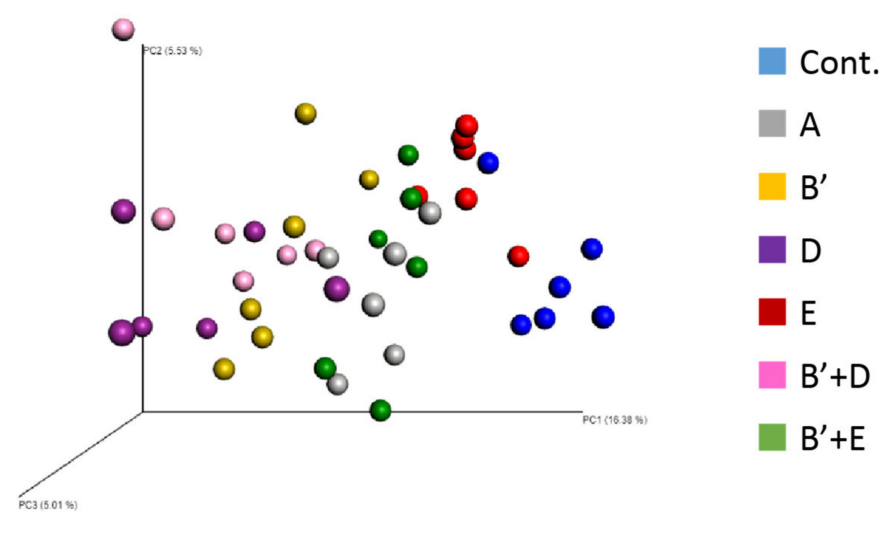

B

Unweighted UniFrac distance

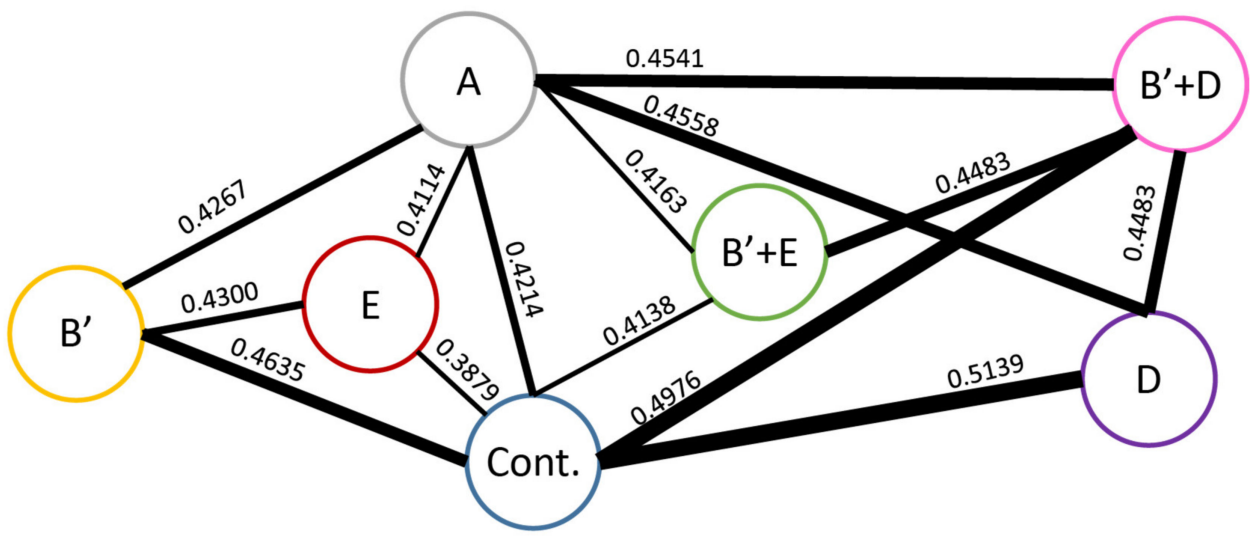

$$
\begin{array}{cl}
\text { Cont. : Cellulose } \\
\text { A } & \text { : Jerusalem artichoke } \\
\text { B' } & \text { : Water-extract } \\
\text { D } & \text { : Organic-extract } \\
\text { E } & \text { : Insoluble-extract }
\end{array}
$$

Figure 9. The water-soluble extract, organic extract component, and their combination resulted in similar change of the microbiota composition. (A) Bacterial beta diversity for comparing each group. PCoA plots of unweighted UniFrac distance metrics obtained from sequencing the 16S rDNA in feces. (Cellulose $(n=6)$, Jerusalem artichoke $(n=6)$, water-soluble extract $(n=6)$, organic extract $(n=6)$, insoluble extract $(n=6)$, water-soluble extract + organic extract $(n=6)$, water-soluble extract + insoluble extract $(n=6))$. (B) The average of unweighted UniFrac distance between groups. The number in (B) indicates the average distance calculated by UniFrac distance metrics. Cellulose, Jerusalem artichoke, water-soluble extract, organic extract, or insoluble extract are Cont., A, B', D, or E, respectively. 
The relative abundance of Bifidobacterium was higher in group A than group E (Figure 10D). The relative abundance of Allobaculum was significantly higher in group A than group B' + D (Figure 10L). The relative abundance of Oscillospira changed significantly for all groups except group E (Figure 10K).

A

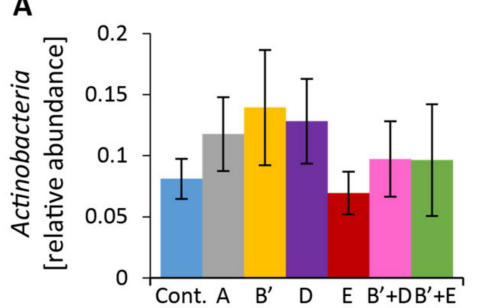

D

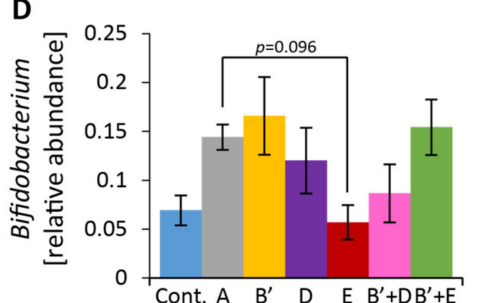

G

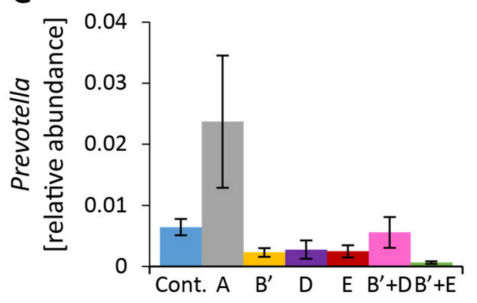

J

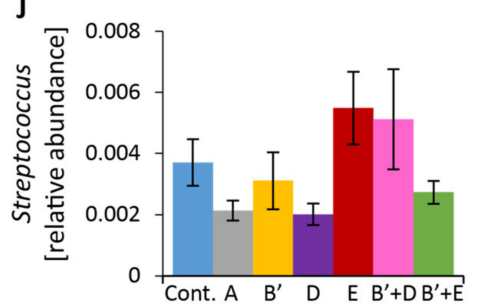

B

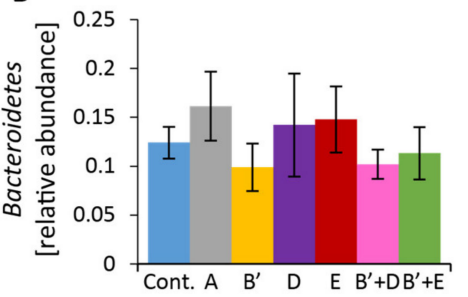

E

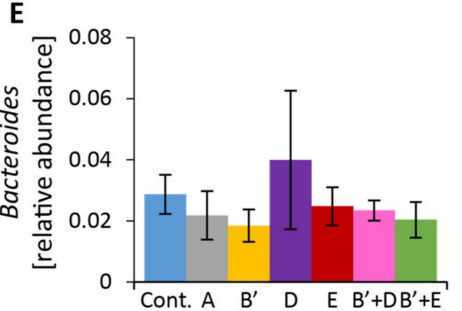

H

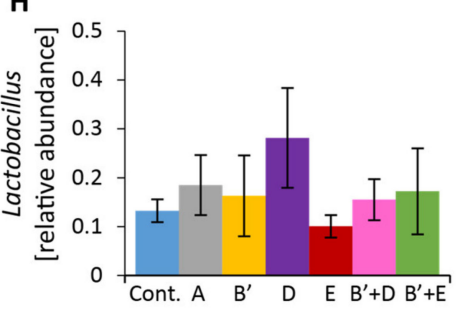

K

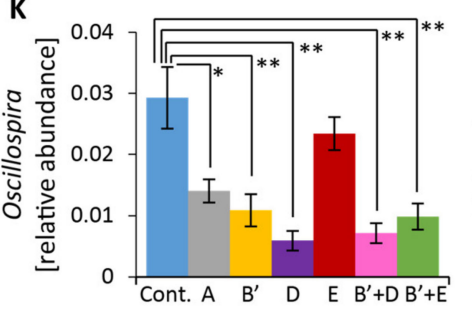

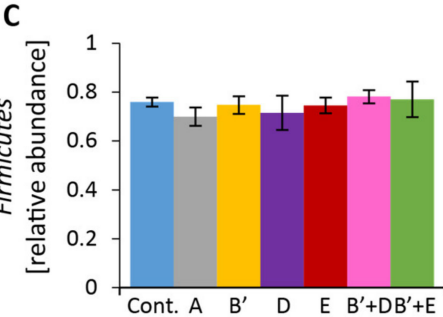

F

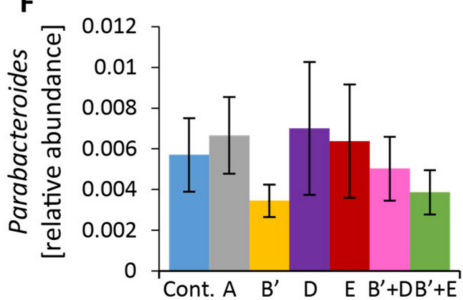

I

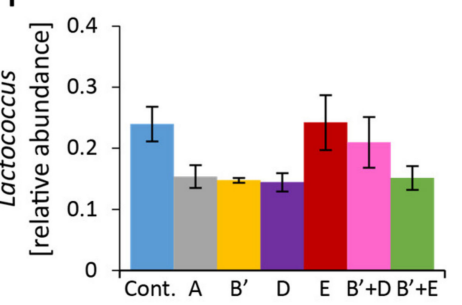

L

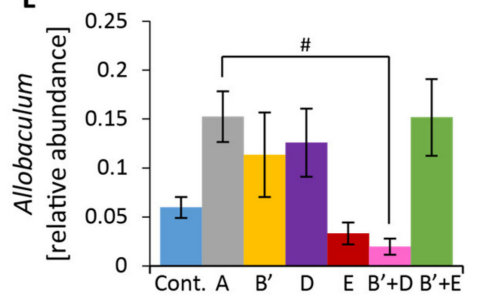

Figure 10. The relative abundance of microbes at the phylum and genus levels was hardly changed upon consumption of the Jerusalem artichoke, water-soluble extract, and organic extract. (A-C) The relative abundance of microbes at the phylum level ((A) Actinobacteria, (B) Bacteroidetes, (C) Firmicutes). (D-L) The relative abundance of microbes at the genus level ((D) Bifidobacterium, (E) Bacteroides, (F) Parabacteroides, (G) Prevotella, (H) Lactobacillus, (I) Lactococcus, (J) Streptococcus, (K) Oscillospira, (L) Allobaculum). All values are represented as mean $\pm \operatorname{SEM}$ (Cellulose $(n=6)$, Jerusalem artichoke $(n=6)$, water-soluble extract $(n=6)$, organic extract $(n=6)$, insoluble extract $(n=6)$, water-soluble extract + organic extract $(n=6)$, water-soluble extract + insoluble extract $(n=6)) .{ }^{* *} p<0.01,{ }^{*} p<0.05$, evaluated using one-way ANOVA with Tukey post-hoc test. \# $p<0.05$, evaluated using the Kruskal-Wallis with Dunn post-hoc test. Cellulose, Jerusalem artichoke, water-soluble extract, organic extract, or insoluble extract are Cont., A, B', D, or E, respectively. 


\section{Discussion}

In the present study, the consumption of Jerusalem artichokes changed gut microbiota, increased concentrations of SCFAs, and decreased cecal $\mathrm{pH}$ in mice fed a HFD. When compared to inulin, interestingly, they were found to differentially impact the bacterial populations in the gut, but they had a similar influence on SCFA content and cecal $\mathrm{pH}$. Reasons for this may be attributed to other bioactive compounds in Jerusalem artichokes known to modulate the microbiota, which is why we chose to fractionate the Jerusalem artichoke into water-soluble, insoluble, and organic-soluble extracts. From this procedure, we discovered the organic extract was primarily responsible for driving the changes in the microbiota composition, and that the organic and water-soluble extracts together boosted the production of SCFAs and lowered cecal $\mathrm{pH}$. On the whole, it can be interpreted that these components play a stronger role in the change of the microbiota than inulin alone.

From the preliminary experiment, it was found that the consumption of Jerusalem artichokes and their individual components increased levels of SCFAs relative to a standard diet. However, the effect of these variables on microbiota composition has not yet been explored. In an earlier study comparing a standard diet, HFD, and HFD + inulin, the results showed each had a differential impact on microbiota composition [36]. In other words, a diet with inulin changed the composition of microbiota in a different manner than that of a standard diet. Given that Jerusalem artichokes contain a fair amount of inulin, we expect the intake of a HFD with Jerusalem artichokes changes to the different microbiota composition from standard diet.

Jerusalem artichoke powder was fractionated into soluble and insoluble components and then combined as food for the mice. Findings revealed that cecal $\mathrm{pH}$ decreased and SCFA content increased. However, the microbiota composition from group B + C was different from that of group A. This outcome may be on account of the ratio of water-soluble to insoluble extracts. The collection rates for the water-soluble and insoluble extracts were $81.9 \%$ and $18.1 \%$, respectively, and in this study, they were combined at a ratio of $1: 1$ and fed to the mice. In previous studies, 1:1 and 3:1 ratios of functional oligosaccharides and insoluble dietary fiber resulted in differences in microbiota compositions [37]. For future experiments, we expect a water-soluble to insoluble extract ratio of 8:2 to have a similar effect to that of Jerusalem artichokes.

Inulin is known to increase the relative abundance of Bifidobacterium [38-40], and in our study, Bifidobacterium was increased upon the consumption of Jerusalem artichokes. This bacterium is known to produce acetic, lactic, and butyric acids [41,42], and we also saw levels lactic and butyric acids increase significantly. It has been reported that feeding yogurt supplemented with Bifidobacterium breve to infants helps prevent gastrointestinal disorders [43], so feeding Jerusalem artichokes to an individual may be equally beneficial in this regard.

Oscillospira is a butyric acid-producing bacterium [44] and studies in humans have uncovered a negative correlation between Oscillospira concentrations and body mass index, indicating that its relative abundance is reduced in obese individuals [45]. Moreover, higher amounts of this bacterium have been observed in the microbiota of constipated women over those who are healthy [46], suggesting that it increases when peristalsis is suppressed. In our study, Oscillospira was decreased upon consumption of Jerusalem artichokes. Therefore, intaking Jerusalem artichokes may improve constipation.

Prevotella is known to be relatively high in the digestive tracts of Asians, Latin Americans, and Africans. Its concentrations increase following intake of foods high in fiber, such as vegetables $[47,48]$. Here, Prevotella was specifically increased by feeding the Jerusalem artichoke, but not by any of its individual components or inulin alone. This finding underscores the importance of eating vegetables in their entirety for promoting gut health and may provide insight as to why the aforementioned population groups have higher levels of Prevotella.

Previous research has shown that $\alpha$-diversity and relative abundances of Lactobacillus and Bifidobacterium are reduced in mice with dextran sodium sulfate (DSS)-induced colitis [49]. Clostridium butyricum, which produces butyric acid, is known to alleviate symptoms of DSS-induced colitis [50,51]. Although Clostridium butyricum was not detected in this study, levels of butyric acid, the relative 
abundance of Bifidobacterium, and $\alpha$-diversity increased following intake of Jerusalem artichokes. Therefore, it is likely that Jerusalem artichokes and/or their individual components are capable of alleviating symptoms of colitis.

A limitation of this study was that we were unable to identify the exact organic components that affected the microbiota. The final collection rate of the organic extract was the lowest out of all the extracts, which is why quite a large amount of Jerusalem artichoke powder is required to identify organic extracts, which is costly and labor intensive. It is presumable that it consisted of lipids, such as essential oils, sesquiterpenes, and caffeoylquinic acids [52,53], based on current evidence. Additionally, previous research has noted that caffeoylquinic acids can increase Bifidobacterium levels [54], so it is possible that this essential oil, in particular, affected microbiota composition. Further investigations are warranted.

\section{Conclusions}

In summary, feeding Jerusalem artichokes changed the microbiota composition, increased SCFA production, and lowered cecal $\mathrm{pH}$ in mice fed a HFD. Components in the Jerusalem artichokes primarily responsible for this outcome, when consumed together, were the water-soluble extract (mainly inulin) and organic extract. This study provides evidence that powdered Jerusalem artichokes, rather than inulin supplements, may be superior for promoting SCFA production and preventing digestive diseases like colitis.

Supplementary Materials: Supplementary materials can be found at http://www.mdpi.com/2076-2607/8/6/954/s1. Figure S1: Consumptions of high-fat diet with cellulose increased cecal $\mathrm{pH}$ and decreased levels of short-chain fatty acids. Table S1: The results of PERMANOVA for the beta diversity index in aim 2. Table S2: The results of PERMANOVA for the beta diversity index in aim 3.

Author Contributions: H.S. and S.S. designed the research, analyzed the data and wrote the manuscript. H.S., Y.L., Y.N. (Yuki Nakayama), A.W. and H.M. performed the experiments. F.N. and Y.N. (Yoichi Nakao) performed the extractions. All authors have read and agreed to the published version of the manuscript.

Funding: This work was partially supported by the Japan Society for the Promotion of Science (JSPS) KAKENHI (A and Houga) (Shibata, S).

Conflicts of Interest: The authors declare no conflict of interest.

\section{References}

1. Hooks, K.B.; O'Malley, M.A. Dysbiosis and its discontents. mBio 2017, 8, e01492-17. [CrossRef]

2. Ley, R.E.; Turnbaugh, P.J.; Klein, S.; Gordon, J.I. Microbial ecology: Human gut microbes associated with obesity. Nature 2006, 444, 1022-1023. [CrossRef]

3. Turnbaugh, P.J.; Ley, R.E.; Mahowald, M.A.; Magrini, V.; Mardis, E.R.; Gordon, J.I. An obesity-associated gut microbiome with increased capacity for energy harvest. Nature 2006, 444, 1027-1031. [CrossRef]

4. Jahani-Sherafat, S.; Alebouyeh, M.; Moghim, S.; Ahmadi Amoli, H.; Ghasemian-Safaei, H. Role of gut microbiota in the pathogenesis of colorectal cancer; A review article. Gastroenterol. Hepatol. Bed Bench 2018, 11, 101-109.

5. Mai, V.; Morris, J.G., Jr. Need for prospective cohort studies to establish human gut microbiome contributions to disease risk. J. Natl. Cancer Inst. 2013, 105, 1850-1851. [CrossRef] [PubMed]

6. Jiang, H.; Ling, Z.; Zhang, Y.; Mao, H.; Ma, Z.; Yin, Y.; Wang, W.; Tang, W.; Tan, Z.; Shi, J.; et al. Altered fecal microbiota composition in patients with major depressive disorder. Brain Behav. Immun. 2015, 48, 186-194. [CrossRef]

7. Koh, A.; De Vadder, F.; Kovatcheva-Datchary, P.; Backhed, F. From dietary fiber to host physiology: Short-chain fatty acids as key bacterial metabolites. Cell 2016, 165, 1332-1345. [CrossRef] [PubMed]

8. Den Besten, G.; van Eunen, K.; Groen, A.K.; Venema, K.; Reijngoud, D.J.; Bakker, B.M. The role of short-chain fatty acids in the interplay between diet, gut microbiota, and host energy metabolism. J. Lipid Res. 2013, 54, 2325-2340. [CrossRef]

9. Cummings, J.H.; Pomare, E.W.; Branch, W.J.; Naylor, C.P.; Macfarlane, G.T. Short chain fatty acids in human large intestine, portal, hepatic and venous blood. Gut 1987, 28, 1221-1227. [CrossRef] [PubMed] 
10. Okada, T.; Fukuda, S.; Hase, K.; Nishiumi, S.; Izumi, Y.; Yoshida, M.; Hagiwara, T.; Kawashima, R.; Yamazaki, M.; Oshio, T.; et al. Microbiota-derived lactate accelerates colon epithelial cell turnover in starvation-refed mice. Nat. Commun. 2013, 4, 1654. [CrossRef] [PubMed]

11. David, L.A.; Maurice, C.F.; Carmody, R.N.; Gootenberg, D.B.; Button, J.E.; Wolfe, B.E.; Ling, A.V.; Devlin, A.S.; Varma, Y.; Fischbach, M.A.; et al. Diet rapidly and reproducibly alters the human gut microbiome. Nature 2014, 505, 559-563. [CrossRef] [PubMed]

12. Gibson, G.R.; Roberfroid, M.B. Dietary modulation of the human colonic microbiota: Introducing the concept of prebiotics. J. Nutr. 1995, 125, 1401-1412. [CrossRef] [PubMed]

13. De Preter, V.; Hamer, H.M.; Windey, K.; Verbeke, K. The impact of pre- and/or probiotics on human colonic metabolism: Does it affect human health? Mol. Nutr. Food Res. 2011, 55, 46-57. [CrossRef] [PubMed]

14. Van Loo, J.; Clune, Y.; Bennett, M.; Collins, J.K. The syncan project: Goals, set-up, first results and settings of the human intervention study. Br. J. Nutr. 2005, 93 (Suppl. 1), S91-S98.

15. Demigne, C.; Jacobs, H.; Moundras, C.; Davicco, M.J.; Horcajada, M.N.; Bernalier, A.; Coxam, V. Comparison of native or reformulated chicory fructans, or non-purified chicory, on rat cecal fermentation and mineral metabolism. Eur. J. Nutr. 2008, 47, 366-374. [CrossRef]

16. Wada, T.; Sugatani, J.; Terada, E.; Ohguchi, M.; Miwa, M. Physicochemical characterization and biological effects of inulin enzymatically synthesized from sucrose. J. Agric. Food Chem. 2005, 53, 1246-1253. [CrossRef] [PubMed]

17. Hoentjen, F.; Welling, G.W.; Harmsen, H.J.; Zhang, X.; Snart, J.; Tannock, G.W.; Lien, K.; Churchill, T.A.; Lupicki, M.; Dieleman, L.A. Reduction of colitis by prebiotics in hla-b27 transgenic rats is associated with microflora changes and immunomodulation. Inflamm. Bowel Dis. 2005, 11, 977-985. [CrossRef]

18. Valcheva, R.; Dieleman, L.A. Prebiotics: Definition and protective mechanisms. Best Pract. Res. Clin. Gastroenterol. 2016, 30, 27-37. [CrossRef]

19. Sasaki, H.; Miyakawa, H.; Watanabe, A.; Nakayama, Y.; Lyu, Y.; Hama, K.; Shibata, S. Mice microbiota composition changes by inulin feeding with a long fasting period under a two-meals-per-day schedule. Nutrients 2019, 11, 2802. [CrossRef] [PubMed]

20. Li, W.; Zhang, J.; Yu, C.; Li, Q.; Dong, F.; Wang, G.; Gu, G.; Guo, Z. Extraction, degree of polymerization determination and prebiotic effect evaluation of inulin from jerusalem artichoke. Carbohydr. Polym. 2015, 121, 315-319. [CrossRef]

21. Shoaib, M.; Shehzad, A.; Omar, M.; Rakha, A.; Raza, H.; Sharif, H.R.; Shakeel, A.; Ansari, A.; Niazi, S. Inulin: Properties, health benefits and food applications. Carbohydr. Polym. 2016, 147, 444-454. [CrossRef]

22. Kleessen, B.; Schwarz, S.; Boehm, A.; Fuhrmann, H.; Richter, A.; Henle, T.; Krueger, M. Jerusalem artichoke and chicory inulin in bakery products affect faecal microbiota of healthy volunteers. Br. J. Nutr. 2007, 98, 540-549. [CrossRef] [PubMed]

23. Vhile, S.G.; Kjos, N.P.; Sørum, H.; Overland, M. Feeding jerusalem artichoke reduced skatole level and changed intestinal microbiota in the gut of entire male pigs. Anim. Int. J. Anim. Biosci. 2012, 6, 807-814. [CrossRef] [PubMed]

24. Valdovska, A.; Jemeljanovs, A.; Pilmane, M.; Zitare, I.; Konosonoka, I.H.; Lazdins, M. Alternative for improving gut microbiota: Use of jerusalem artichoke and probiotics in diet of weaned piglets. Pol. J. Vet. Sci. 2014, 17, 61-69. [CrossRef] [PubMed]

25. Barszcz, M.; Taciak, M.; Skomiał, J. The effects of inulin, dried jerusalem artichoke tuber and a multispecies probiotic preparation on microbiota ecology and immune status of the large intestine in young pigs. Arch. Anim. Nutr. 2016, 70, 278-292. [CrossRef] [PubMed]

26. Brownlee, I.A. The physiological roles of dietary fibre. Food Hydrocoll. 2011, 25, 238-250. [CrossRef]

27. Dukas, L.; Willett, W.C.; Giovannucci, E.L. Association between physical activity, fiber intake, and other lifestyle variables and constipation in a study of women. Am. J. Gastroenterol. 2003, 98, 1790-1796. [CrossRef]

28. Chang, S.; Cui, X.; Guo, M.; Tian, Y.; Xu, W.; Huang, K.; Zhang, Y. Insoluble dietary fiber from pear pomace can prevent high-fat diet-induced obesity in rats mainly by improving the structure of the gut microbiota. $J$. Microbiol. Biotechnol. 2017, 27, 856-867. [CrossRef]

29. Cabello-Hurtado, F.; Durst, F.; Jorrín, J.V.; Werck-Reichhart, D. Coumarins in Helianthus tuberosus: Characterization, induced accumulation and biosynthesis. Phytochemistry 1998, 49, 1029-1036. [CrossRef] 
30. Kapusta, I.; Krok, E.S.; Jamro, D.B.; Cebulak, T.; Kaszuba, J.; Salach, R.T. Identification and quantification of phenolic compounds from jerusalem artichoke (Helianthus tuberosus L.) tubers. J. Food Agric. Environ. 2013, $11,601-606$.

31. Suseelan, K.N.; Mitra, R.; Pandey, R.; Sainis, K.B.; Krishna, T.G. Purification and characterization of a lectin from wild sunflower (Helianthus tuberosus L.) tubers. Arch. Biochem. Biophys. 2002, 407, 241-247. [CrossRef]

32. Huazano, A.; López, M.G. Metabolism of short chain fatty acids in colon and faeces of mice after a supplementation of diets with agave fructans. Lipid Metab. 2013, 8, 163-182.

33. Nishijima, S.; Suda, W.; Oshima, K.; Kim, S.W.; Hirose, Y.; Morita, H.; Hattori, M. The gut microbiome of healthy japanese and its microbial and functional uniqueness. DNA Res. Int. J. Rapid Publ. Rep. Genes Genomes 2016, 23, 125-133. [CrossRef] [PubMed]

34. Caporaso, J.G.; Kuczynski, J.; Stombaugh, J.; Bittinger, K.; Bushman, F.D.; Costello, E.K.; Fierer, N.; Pena, A.G.; Goodrich, J.K.; Gordon, J.I.; et al. Qiime allows analysis of high-throughput community sequencing data. Nat. Methods 2010, 7, 335-336. [CrossRef]

35. Edgar, R.C. Search and clustering orders of magnitude faster than blast. Bioinformatics 2010, 26, $2460-2461$. [CrossRef] [PubMed]

36. Hamilton, M.K.; Ronveaux, C.C.; Rust, B.M.; Newman, J.W.; Hawley, M.; Barile, D.; Mills, D.A.; Raybould, H.E. Prebiotic milk oligosaccharides prevent development of obese phenotype, impairment of gut permeability, and microbial dysbiosis in high fat-fed mice. Am. J. Physiol. Gastrointest. Liver Physiol. 2017, 312, G474-G487. [CrossRef]

37. Cheng, W.; Lu, J.; Li, B.; Lin, W.; Zhang, Z.; Wei, X.; Sun, C.; Chi, M.; Bi, W.; Yang, B.; et al. Effect of functional oligosaccharides and ordinary dietary fiber on intestinal microbiota diversity. Front. Microbiol. 2017, 8, 1750. [CrossRef]

38. Gibson, G.R.; Beatty, E.R.; Wang, X.; Cummings, J.H. Selective stimulation of bifidobacteria in the human colon by oligofructose and inulin. Gastroenterology 1995, 108, 975-982. [CrossRef]

39. Zhu, L.; Qin, S.; Zhai, S.; Gao, Y.; Li, L. Inulin with different degrees of polymerization modulates composition of intestinal microbiota in mice. FEMS Microbiol. Lett. 2017, 364, 75-82. [CrossRef]

40. Zhang, S.; Yang, J.; Henning, S.M.; Lee, R.; Hsu, M.; Grojean, E.; Pisegna, R.; Ly, A.; Heber, D.; Li, Z. Dietary pomegranate extract and inulin affect gut microbiome differentially in mice fed an obesogenic diet. Anaerobe 2017, 48, 184-193. [CrossRef]

41. O'Callaghan, A.; van Sinderen, D. Bifidobacteria and their role as members of the human gut microbiota. Front. Microbiol. 2016, 7, 925. [CrossRef]

42. Lee, K.Y.; So, J.S.; Heo, T.R. Thin layer chromatographic determination of organic acids for rapid identification of bifidobacteria at genus level. J. Microbiol. Methods 2001, 45, 1-6. [CrossRef]

43. Wang, C.; Shoji, H.; Sato, H.; Nagata, S.; Ohtsuka, Y.; Shimizu, T.; Yamashiro, Y. Effects of oral administration of bifidobacterium breve on fecal lactic acid and short-chain fatty acids in low birth weight infants. J. Pediatric Gastroenterol. Nutr. 2007, 44, 252-257. [CrossRef] [PubMed]

44. Gophna, U.; Konikoff, T.; Nielsen, H.B. Oscillospira and related bacteria-from metagenomic species to metabolic features. Environ. Microbiol. 2017, 19, 835-841. [CrossRef] [PubMed]

45. Konikoff, T.; Gophna, U. Oscillospira: A central, enigmatic component of the human gut microbiota. Trends Microbiol. 2016, 24, 523-524. [CrossRef] [PubMed]

46. Parthasarathy, G.; Chen, J.; Chen, X.; Chia, N.; O'Connor, H.M.; Wolf, P.G.; Gaskins, H.R.; Bharucha, A.E. Relationship between microbiota of the colonic mucosa vs feces and symptoms, colonic transit, and methane production in female patients with chronic constipation. Gastroenterology 2016, 150, 367-379. [CrossRef] [PubMed]

47. Arumugam, M.; Raes, J.; Pelletier, E.; Le Paslier, D.; Yamada, T.; Mende, D.R.; Fernandes, G.R.; Tap, J.; Bruls, T.; Batto, J.M.; et al. Enterotypes of the human gut microbiome. Nature 2011, 473, 174-180. [CrossRef]

48. Wu, G.D.; Chen, J.; Hoffmann, C.; Bittinger, K.; Chen, Y.Y.; Keilbaugh, S.A.; Bewtra, M.; Knights, D.; Walters, W.A.; Knight, R.; et al. Linking long-term dietary patterns with gut microbial enterotypes. Science 2011, 334, 105-108. [CrossRef]

49. Cai, X.; Han, Y.; Gu, M.; Song, M.; Wu, X.; Li, Z.; Li, F.; Goulette, T.; Xiao, H. Dietary cranberry suppressed colonic inflammation and alleviated gut microbiota dysbiosis in dextran sodium sulfate-treated mice. Food Funct. 2019, 10, 6331-6341. [CrossRef] 
50. Kuroiwa, T.; Kobari, K.; Iwanaga, M. [Inhibition of enteropathogens by clostridium butyricum miyairi 588]. Kansenshogaku zasshi. J. Jpn. Assoc. Infect. Dis. 1990, 64, 257-263. [CrossRef]

51. Hayashi, A.; Sato, T.; Kamada, N.; Mikami, Y.; Matsuoka, K.; Hisamatsu, T.; Hibi, T.; Roers, A.; Yagita, H.; Ohteki, T.; et al. A single strain of clostridium butyricum induces intestinal il-10-producing macrophages to suppress acute experimental colitis in mice. Cell Host Microbe 2013, 13, 711-722. [CrossRef] [PubMed]

52. Helmi, Z.; Al Azzam, K.M.; Tsymbalista, Y.; Ghazleh, R.A.; Shaibah, H.; Aboul-Enein, H. Analysis of essential oil in jerusalem artichoke (Helianthus tuberosus L.) leaves and tubers by gas chromatography-mass spectrometry. Adv. Pharm. Bull. 2014, 4, 521-526. [PubMed]

53. Chen, F.J.; Long, X.H.; Li, E.Z. Evaluation of antifungal phenolics from Helianthus tuberosus L. Leaves against phytophthora capsici leonian by chemometric analysis. Molecules 2019, 24, 4300. [CrossRef]

54. Mills, C.E.; Tzounis, X.; Oruna-Concha, M.J.; Mottram, D.S.; Gibson, G.R.; Spencer, J.P. In vitro colonic metabolism of coffee and chlorogenic acid results in selective changes in human faecal microbiota growth. Br. J. Nutr. 2015, 113, 1220-1227. [CrossRef] [PubMed]

(C) 2020 by the authors. Licensee MDPI, Basel, Switzerland. This article is an open access article distributed under the terms and conditions of the Creative Commons Attribution (CC BY) license (http://creativecommons.org/licenses/by/4.0/). 